\title{
EVALUATION OF NUTRITION AND HEALTH RELATED NUTRITIOUS INTAKE KNOWLEDGE AMONG ATHLETES' TRAINERS
}

\author{
Ahmed Boumaeza ${ }^{1}$, \\ Ali Ruhaet ${ }^{1}$, \\ Hassan Abdulqader ${ }^{1}$, \\ Abdelmetalab F. Tarhuni' ${ }^{2}$, \\ Isam Danna ${ }^{3}$, \\ Abdulla Sheikhi', \\ Ali Ateia Elmabsout ${ }^{1 \mathrm{i}}$ \\ ${ }^{1}$ Department of Nutrition, \\ Faculty of Public Health, \\ University of Benghazi, \\ Benghazi, Libya \\ ${ }^{2}$ Department of Environment Health, \\ Faculty of Public Health, \\ University of Benghazi, \\ Benghazi, Libya \\ ${ }^{3}$ Department of Community and Family Medicine, \\ Faculty of Medicine, University of Benghazi, \\ Benghazi, Libya \\ ${ }^{4}$ Curtin University, \\ Perth, Western Australia, \\ Australia
}

\begin{abstract}
:
Background: Individuals who have valuable knowledge on how the importance of adequate and balanced diet and this knowledge will on their behaviors which eventually considered to be more successful in sports life. The present study aims to evaluate the nutrition and nutrients imbalance related to the health knowledge among trainers' athletes. Methods: The study sample consists of 203 voluntary trainers from the sport clubs and gyms. Modified questionnaire was used in the study and Chi-square and Pearson correlation test was used. Results: Athletes related fields were determined to have the lack of knowledge on nutrition and also nutrients deficit related to ill-health questions. It was more likely the trainers know some aspects of foods and nutrients such as role and sources of some foods, but the overall score showed $40-50 \%$ for nutritional
\end{abstract}

i Correspondence: email ali.elmabsout@uob.edu.ly 
knowledge questions. Furthermore, questions related to ill-health showed poor score $(<$ $40 \%$ ). There was no gender difference in related nutrition knowledge questions and also questions for nutrient and ill-health. However, significant_differences were found between education levels in which positive correlation $\mathrm{R}=0.2(\mathrm{P}<0.05)$ between question for nutrition knowledge, nutrient related to health outcomes and high levels of education. Conclusion: The athlete's trainers have regular nutrition knowledge and poor health related nutrients disorders knowledge. While gender differences did not influence neither nutrition knowledge nor health related nutrients deficient questions, the education levels found to have significant impact on both nutrition knowledge and health related nutrients deficient. Furthermore, dietitians with an expertise in athletes' nutrition are qualified professionals who should be the primary source for obtaining diet information and subsequently monitoring.

Keywords: nutrition, knowledge, health, health outcomes, questions

\section{Introduction}

Sports nutrition is relatively a new field in which involving the application of nutritional principles to enhance the athletic performance (1). In fact, nutrition can influence athletes in many ways. In this respect, it does play an important role in achieving and maintaining health. In addition, an optimal nutrition can help in reducing fatigue, allowing a sportsman to train and compete longer or recover faster between training sessions (2). Furthermore, foods and nutrition are an important component of any physical fitness program. Hence, the target of any dietary goal of active individuals is to obtain sufficient nutrition for optimizing the health, fitness and sports performance (3).

In order to know how nutrition is important for the athletes, there should be un understanding of the effect of nutrition on every process in the body from energy production and recovery from exercise (4).

In some circumstances the nutritional advice is not followed and this may be due to the lack of knowledge or information, and interest for achievement the change in the diets, or certain perceived or encountered barriers lets people preventing from eating healthier diets such as lack of time (too busy with work) or money (cost), or taste (5). Athletes sometimes rely on coaches for nutrition guidance in certain training program (6). Indeed, if the coaches have misinformed about nutrition, this becomes a potential problem for athletes, as well (7).

Nutrition training or alternatively sports nutrition can be carried out for the individuals via regular and extensive educational programs as well as the individual training himself on his own settings (8).

There are a wide range of questions related nutritional knowledge and disorder of nutrient intake knowledge. An Understanding athletes' nutrition knowledge, and health outcome due to intake nutrient imbalance and barrier influence on dietary intake will 
inform nutrition-education programs in this population However, scarce data were available locally in Libya that assessed if the levels of knowledge have had altered by different educational levels in athletes' trainers. As well, there is no data demonstrated that levels of nutritional knowledge result would be affected by gender differences. Therefore, the aim of the present study is to evaluate the nutrition and health related nutritious intake knowledge among athletes' trainers.

\section{Materials and methods}

\subsection{Study population}

A cross sectional study carried out from end of Beginning of January 2020 to end of April 2020 on numbers of Benghazi clubs and Gyms in Benghazi the second largest city in Libya.

Approached of our study is a group of athletes' trainers. The samples 205 subjects (137 male and 66 female) and the age of patients ranging between 18-51 years were involved in the study. After obtaining written consent, the subjects were requested to fill out a questionnaire and final completed questionnaires in hand were 203. Hence, our overall response rate was $99 \%$.

\subsection{Questionnaire}

The questionnaire for this study based on 20 items with two sections Section one questions related to nutrition knowledge, section two questions related to nutrients related to health outcome. The questionnaire also contained questions about personal information, socioeconomic factors. The questionnaire in this study was modified and adapted according to Parmenter et al. (9) and updated by Christine et al. (10).

\subsection{Score evaluation}

The correct answer was ranked and compared to wrong and non-response answer. The score was based on the right response as following (10).

Excellent $>80$,

Very good $70-79$,

Good $60-69$,

Satisfactory $50-59$,

Regular $40-49$,

Poor $30-39$,

Very poor 20 - 29,

Bad $<20$. 


\subsection{Ethical statement}

This study was approval by the local Ethics Committee of the Benghazi province. Informed written consent was obtained through a consent form that was given to the participants along with the questionnaire.

\subsection{Statistical analysis}

The data from the questionnaires was entered using Excel. Data set was exported to SPSS v.22 and Epi-info for complete analysis. Statistical analysis was carried out for the complete sample. Frequencies and percentages were used for qualitative data and Chisquare test was performed. Pearson correlation was performed for quantitative data and expressed as mean \pm SD. For statistically significant differences was done at $p \leq 0.05$ between the correct answer and other answers for the same questions. The tables present only score for the correct answer for each question and numbers of respondents by trainers.

\section{Results}

\subsection{Distribution of age and gender and education levels of the trainers}

203 trainers were involved in this study. The mean age $28 \pm 8$ years old with age ranging between age 18-51 years old. The age groups between 18-25 (43\%) and 26-40 years old shown almost same trends. However, those with age groups between 41-51 years old being the least (11\%) (Table 1). Regarding the gender, more male than female participate in the study by which 1:2. (Table 2). In Table 3, the highest percentages of the trainers were found have university levels $(26.1 \%)$, come in the next those with secondary education levels $(26.6 \%)$ while the primary presented the lowest groups $(11.3 \%)$.

Table 1: Scio-demographic and types of physical' activates of the trainers

\begin{tabular}{|l|l|c|c|}
\hline \multicolumn{2}{|c|}{} & $\mathbf{N}$ & Percent (\%) \\
\hline \multirow{3}{*}{ Age categories } & $18-25$ & 87 & 42.9 \\
\cline { 2 - 4 } & $26-40$ & 94 & 46.3 \\
\cline { 2 - 4 } & $41-51$ & 22 & 10.8 \\
\cline { 2 - 4 } & Total & 203 & 100.0 \\
\hline
\end{tabular}

Table 2: Gender distribution of the trainers

\begin{tabular}{|l|l|c|c|}
\hline \multicolumn{2}{|c|}{} & $\mathbf{N}$ & Percent (\%) \\
\hline \multirow{3}{*}{ Gender } & Male & 137 & 67.5 \\
\cline { 2 - 4 } & Female & 66 & 32.5 \\
\cline { 2 - 4 } & Total & 203 & 100.0 \\
\hline
\end{tabular}


Ahmed Boumaeza, Ali Ruhaet, Hassan Abdulqader,

Abdelmetalab F. Tarhuni, Isam Danna, Abdulla Sheikhi, Ali Ateia Elmabsout

EVALUATION OF NUTRITION AND HEALTH RELATED NUTRITIOUS INTAKE KNOWLEDGE AMONG ATHLETES' TRAINERS

Table 3: Education levels of the trainers

\begin{tabular}{|l|c|c|}
\hline & N & Percent (\%) \\
\hline Primary & 23 & 11.3 \\
\hline Secondary & 54 & 26.6 \\
\hline University & 126 & 62.1 \\
\hline Total & 203 & 100.0 \\
\hline
\end{tabular}

\subsection{Types of physical activities and nutrition and health knowledge related questions:}

According to the types of physical activities performed by the trainers, there were more than half or the participant participate in body building, $21.7 \%$ play football, and $18.2 \%$ do walking (Table 4).

Health problems related to nutrients intake found that the right answer was significant high in numbers of questions which include health problems related to calcium deficiency and osteopenia $(48.8 \%)$ and high sugar consumption and obesity (57.1\%) $P<0.05$ by which the answer present as regular and satisfactory knowledge. While the other questions the response rate for the right answer was less and not significant $(P<0.05)$ in which the right answer was less than $40 \%$ indicate poor knowledge (Table 5).

The nutritional knowledge questions presented in table 6A-D. In regarding nutritional knowledge of the trainers, found in table $6 \mathrm{~A}$, vitamin $\mathrm{D}$ for bone received the correct answer on (51.7\%), has the only significant satisfactory knowledge score among trainers $(P<0.05)$, whereas question regarding source of zinc received $54.7 \%$ but not significant $(\mathrm{P}<0.05)$. The other questions in Table 6 reported regular score and shown less than $50 \%$ responses. However, the mean \pm SD of score for health problems related to imbalance nutrients intake was (Poor) above 30\%, while score for nutritional knowledge was (regular) above $40 \%$.

In Table 6B, there were a number of questions have been respondent with significant differences and found that question with good knowledge score include questions response rate $60 \%$ and more such as some vitamin considered as antioxidants $(P<0.05)$. While there were questions with satisfactory score for nutrition knowledge include the correct answer for benefit of saturated fatty acids (59.8\%) and best sources of starches $(58.6 \%)(P<0.05)$. Even though, the rest of questions have significant values but have regular score in which the correct answer received less than $50 \%$.

Poor, very poor and bad score for nutrition knowledge questions presented mainly in Table 6C, the answers for those questions in which response rate or correct answer were less than $40 \%$. The questions in Table $6 \mathrm{C}$, received non-significant correct answer with poor, very poor and bad nutritional score $(P<0.05)$.

Further analysis of nutritional knowledge as shown in Table 6D revealed that the correct answer for satisfactory nutritional knowledge score $(52.7 \%)(P=0.001)$ for question related to recommendation of type of milk consumption. Other questions listed in Table $6 \mathrm{D}$, the correct answer responded between bad, very poor and poor nutritional knowledge ranging between $16.7 \%$ as in question saturated fat found mainly in dairy 
Ahmed Boumaeza, Ali Ruhaet, Hassan Abdulqader,

Abdelmetalab F. Tarhuni, Isam Danna, Abdulla Sheikhi, Ali Ateia Elmabsout

EVALUATION OF NUTRITION AND HEALTH RELATED NUTRITIOUS

INTAKE KNOWLEDGE AMONG ATHLETES' TRAINERS

products, of meal with high fiber low in fat, and food do not contain healthy fat (39.4\%) which was poor score, and very poor score was on the correct answer for meal with high fiber low fat question (22.6\%).

Table 4: Types of physical activities

\begin{tabular}{|l|c|c|}
\hline Types of physical activities & N & Percent (\%) \\
\hline Football & 44 & 21.7 \\
\hline Body building & 108 & 53.2 \\
\hline Walking & 37 & 18.2 \\
\hline Others & 14 & 6.9 \\
\hline Total & 203 & 100.0 \\
\hline
\end{tabular}

Table 5: Health problems related to disorder of nutrient intakes

\begin{tabular}{|l|c|c|c|}
\hline Health problems & $\begin{array}{c}\text { Numbers of responses } \\
\text { with correct answer }\end{array}$ & Score & $\begin{array}{c}\text { P } \\
\text { values }\end{array}$ \\
\hline $\begin{array}{l}\text { Health problems associated } \\
\text { with high sodium intake. }\end{array}$ & 57 & $28.1 \%$ & 0.9 \\
\hline $\begin{array}{l}\text { Health problems associated } \\
\text { with low fiber. }\end{array}$ & 80 & $39.4 \%$ & 0.09 \\
\hline $\begin{array}{l}\text { Health problems associated } \\
\text { with iron deficiency. }\end{array}$ & 63 & $31.0 \%$ & 0.8 \\
\hline $\begin{array}{l}\text { Health problems associated } \\
\text { with iodide deficiency. }\end{array}$ & 44 & $21.7 \%$ & 0.9 \\
\hline $\begin{array}{l}\text { Health problems associated } \\
\text { with calcium deficiency. }\end{array}$ & 99 & $48.8 \%$ & 0.000 \\
\hline $\begin{array}{l}\text { Health problems associated } \\
\text { with high sugar consumption. }\end{array}$ & 116 & $57.1 \%$ & 0.000 \\
\hline $\begin{array}{l}\text { Health problems associated } \\
\text { with high fat intake. }\end{array}$ & 76 & $37.4 \%$ & 0.8 \\
\hline
\end{tabular}

Note: Chi-square test was performed between groups at $\alpha<0.05$ which considered significant. Score only for the correct answer.

Table 6A: Nutritional knowledge questions

\begin{tabular}{|l|c|c|c|}
\hline Nutritional knowledge questions (part 1) & $\begin{array}{c}\text { Numbers of responses } \\
\text { with correct answer }\end{array}$ & Score & $\begin{array}{c}\text { P } \\
\text { values }\end{array}$ \\
\hline Do you know vitamin D is good for bone. & 105 & $51.7 \%$ & 0.000 \\
\hline Which one is a major source of energy. & 85 & $41.9 \%$ & 0.9 \\
\hline Which food contain most fibers. & 84 & $41.4 \%$ & 0.06 \\
\hline Which food contains high sugar. & 82 & $40.4 \%$ & 0.07 \\
\hline Do you know source of zinc? & 110 & $54.7 \%$ & 0.07 \\
\hline $\begin{array}{l}\text { Is the Sun considered to be source } \\
\text { of vitamin C. }\end{array}$ & 98 & $48.3 \%$ & 0.1 \\
\hline
\end{tabular}

Note: Chi-square test was performed between groups at $\alpha<0.05$ which considered significant. Score only for the correct answer. 
Ahmed Boumaeza, Ali Ruhaet, Hassan Abdulqader, Abdelmetalab F. Tarhuni, Isam Danna, Abdulla Sheikhi, Ali Ateia Elmabsout EVALUATION OF NUTRITION AND HEALTH RELATED NUTRITIOUS INTAKE KNOWLEDGE AMONG ATHLETES' TRAINERS

Table 6B: Nutritional knowledge questions

\begin{tabular}{|l|c|c|c|}
\hline Nutritional knowledge questions (part 2) & $\begin{array}{c}\text { Numbers of } \\
\text { responses to } \\
\text { correct answer }\end{array}$ & Score & $\begin{array}{c}\text { P } \\
\text { values }\end{array}$ \\
\hline $\begin{array}{l}\text { Do you know that some foods contain highest } \\
\text { fat contents but less cholesterol? }\end{array}$ & 98 & $48.3 \%$ & 0.04 \\
\hline Which foods help in lowering cholesterol level? & 83 & $40.9 \%$ & 0.03 \\
\hline Is it true some vitamin is considered as antioxidants? & 127 & $62.6 \%$ & 0.000 \\
\hline Is it recommended to increase intake of saturated fat acids? & 119 & $59.8 \%$ & 0.000 \\
\hline Which food is best source for starch? & 119 & $58.6 \%$ & 0.000 \\
\hline Which food contain high salt content? & 90 & $44.3 \%$ & 0.000 \\
\hline What is the best alternative foods for red meat is? & 79 & $38.9 \%$ & 0.8 \\
\hline
\end{tabular}

Note: Chi-square test was performed between groups at $\alpha<0.05$ which considered significant. Score only for the correct answer.

Table 6C: Nutritional knowledge questions

\begin{tabular}{|l|c|c|c|}
\hline Nutritional knowledge questions (part 3) & $\begin{array}{c}\text { Numbers of responses } \\
\text { to correct answer }\end{array}$ & Score & $\begin{array}{c}\text { P } \\
\text { values }\end{array}$ \\
\hline Do you know the benefits of vitamin B9? & 62 & $30.8 \%$ & 0.9 \\
\hline When the water intake is increased. & 83 & $40.9 \%$ & 0.9 \\
\hline Is brown sugar an alternative to white sugar. & 30 & $14.8 \%$ & 0.8 \\
\hline $\begin{array}{l}\text { Is one cup of fruit juice can replace one } \\
\text { serve of a whole fresh fruit. }\end{array}$ & 72 & $35.5 \%$ & 0.9 \\
\hline $\begin{array}{l}\text { Which type of bread has more minerals and } \\
\text { vitamins? }\end{array}$ & 56 & $27.7 \%$ & 0.1 \\
\hline What vitamin derived from animal sources? & 76 & $38.5 \%$ & 0.08 \\
\hline
\end{tabular}

Note: Chi-square test was performed between groups at $\alpha<0.05$ which considered significant. Score only for the correct answer.

Table 6D: Nutritional knowledge questions

\begin{tabular}{|l|c|c|c|}
\hline Nutritional knowledge questions (part 4) & $\begin{array}{c}\text { Numbers of responses } \\
\text { to correct answer }\end{array}$ & Score & $\begin{array}{c}\text { P } \\
\text { values }\end{array}$ \\
\hline $\begin{array}{l}\text { Is it recommended that the milk } \\
\text { should be consumed as low fat milk. }\end{array}$ & 107 & $52.7 \%$ & 0.001 \\
\hline What is the meal with high fibers and low fat? & 45 & $22.2 \%$ & 0.9 \\
\hline Which of the food don't contain healthy fat. & 80 & $39.4 \%$ & 0.08 \\
\hline $\begin{array}{l}\text { Did the saturated fat find mainly in animal } \\
\text { foods. }\end{array}$ & 34 & $16.7 \%$ & 0.1 \\
\hline What is the important fat for human. & 93 & $45.8 \%$ & 0.02 \\
\hline
\end{tabular}

Note: Chi-square test was performed between groups at $\alpha<0.05$ which considered significant. Score only for the correct answer.

\section{Relationship between gender, nutrition, health outcome knowledge}

Looking at the relationship between health problems of imbalance of nutrient intake, nutritional knowledge and genders (Table 7) the result did show that there were no statistically significant differences between gender and nutritional knowledge and 
nutrients imbalance( $P=0.9$ and 0.48 respectively). These scores considered poor for health problems related nutrient disorders and regular score for nutritional knowledge. .Furthermore, similarly has been performed for education levels as shown in Table 8 . There was increased nutritional knowledge among higher degree of education (University) $P=0.044$, and for health problems of nutrients intake and education levels it was observed university levels still have higher score than primary and secondary levels $(P=0.022)$ (Table 8$)$. However, this score falls under regular knowledge.

Table 7: Relationship between Health problems related to disorder of nutrient intakes, nutrition knowledge and gender distribution

\begin{tabular}{|l|c|c|c|}
\hline Model & $\begin{array}{c}\text { Male (score) } \\
\text { Mean } \pm \text { SD }\end{array}$ & $\begin{array}{c}\text { Female (score) } \\
\text { Mean } \pm \text { SD }\end{array}$ & $\begin{array}{c}\text { P } \\
\text { values }\end{array}$ \\
\hline Health problems related to disorder of nutrient intakes & $38.5 \% \pm 2$ & $36 \% \pm 3$ & 0.48 \\
\hline Nutritional knowledge questions & $41 \% \pm 4$ & $41.8 \pm 5$ & 0.9 \\
\hline
\end{tabular}

Pearson Correlation test was performed between groups at $\alpha<0.05$ which considered significant.

Table 8: Relationship between Health problems related to disorder of nutrient intakes and education levels

\begin{tabular}{|l|c|c|c|c|}
\hline $\begin{array}{l}\text { Model/ } \\
\text { level of educations }\end{array}$ & $\begin{array}{c}\text { Primary } \\
\text { (score) } \\
\text { Mean } \pm \text { SD }\end{array}$ & $\begin{array}{c}\text { Secondary } \\
\text { (score) } \\
\text { Mean } \pm \text { SD }\end{array}$ & $\begin{array}{c}\text { University } \\
\text { (score) } \\
\text { Mean } \pm \text { SD }\end{array}$ & $\begin{array}{c}\text { P } \\
\text { values }\end{array}$ \\
\hline $\begin{array}{l}\text { Health problems related to } \\
\text { disorder of nutrient intakes }\end{array}$ & $30.5 \% \pm 2$ & $32 \% \pm 3$ & $41.6 \% \pm 6$ & 0.022 \\
\hline $\begin{array}{l}\text { Nutritional knowledge } \\
\text { questions }\end{array}$ & $40 \% \pm 4$ & $35.8 \pm 5$ & $45 \% \pm 7$ & 0.044 \\
$(\mathrm{R}=0.1)$ \\
\hline
\end{tabular}

Note: Pearson Correlation test was performed between groups at $\alpha<0.05$ which considered significant.

\section{Discussion}

This is the first study to investigate the understanding of nutrition information, nutrition knowledge and health related nutrients disorders among athlete's trainers.

The overall nutrition knowledge score in the current study is inconsistent with previous research in the athletic population $(9,11)$. Spendlove et al. (12) investigated male and female elite Australian athletes from State sporting institutes, National Rugby League and Australian Surf Life Saving who scored an average 62.1\% for section one to three of the general nutritional knowledge questionnaire (GNKQ) (65.4\%, 60.9\% and $60.0 \%$ for section one, two and three respectively) and an average $67.9 \%$ for section one to three of the R-GNKQ $(67.9 \%, 73.6 \%$ and $68.0 \%$ for section one, two and three respectively). These questions were similar to our questions as the present study where we demonstrated less score than the result obtained by Spendlove et al., and Raymond et al. $(12,13)$. Furthermore, collegiate athletes of varying levels and athletes scored $51.5 \%$ for the same three sections of the GNKQ in UK(14) whereas a study validating the same 
GNKQ on an Australian community sample (of predominantly females) report a score of $67 \%$ for these same three sections (15).

In comparison, athletes in the current study scored lower than other elite Australian sports people researched by Spendlove et al. (12), particularly the other sections include sources of nutrients and energy intake. These sections include a large portion of questions regarding knowledge of fats, which is one area highlighted as a weakness in the current study. Furthermore, both gender of athletes was included in the current study compared to Previous research with Australian athletes and community where a large percentage of their participants were female.

Both male and female nutrition knowledge has been reported to equally in the present study. In the work done by Hendrie et al. found that female nutritional knowledge higher than male nutrition knowledge, potentially due to higher interest in nutritional composition of foods and nutrition for optimal health and body composition and may explain some of this difference (15). The athletes' nutrition knowledge section of the questionnaire originally developed by Shifflett and colleagues (16) and update by Christine et al. (10), reported that college athletes scored on average $55 \%$, while the elite AF athletes in the current study scored slightly higher for this section with $61.8 \%(17,18)$. There is limited published research on nutrition knowledge of the athletes' trainers. Only two studies, in addition to Spendlove et al. (12), have reported nutrition knowledge in elite athletes, both conducted in New Zealand approximately 25 years ago $(19,20)$. It is difficult to make comparisons as findings are dated and different tools assessing nutrition knowledge were employed. Regardless, average nutrition knowledge scores of $60 \%$ and $67 \%$ were reported $(21,22)$.

Within the findings of the current study, overall nutrition messages appear to be well understood, but areas of knowledge deficiency are evident. Therefore, according to our knowledge the section of health related nutrient deficient was not covered in literature. Consequently, our athletes have graded as poor score in this section by their recordings. Furthermore, the relation between education levels and nutrition and health related nutrients deficient questions have been shown that increased level of education led to significant increase in both nutritional and health related nutrients deficient knowledge. In fact, this finding similar to result obtained in numbers of publications (2327).

Overall, the nutrition knowledge questions and health related nutritional disorders were given different score by which less than $50 \%$ from regular to poor knowledge.

The questionnaires helped us realize that the level of the nutritional knowledge is not homogeneous in our interviewees. The evolution of new knowledge about athletes' nutrition usually starts with a basic concept that must be further refined; to move from individual nutrients to food, from 'one size fits all' to the individual needs and practices of different athletes, and from single issues to an integrated picture of sports nutrition. The transition from theory to practice usually requires an educational program. 
Therefore, of absolute importance are sources of information from which the athletes practicing trainers can learn about nutrition. Therefore, it is very important that these sources are constantly being updated and that athletes followed them up during their training. Nutrition professionals (e.g. dietitian) should be cautious when giving nutritional advices to athletes. However, dietitians within a sport setting may not be available to the players and thus have limited time to provide nutrition education to the trainer.

There are some study limitations. This investigation is based on subjects' selfreports and it is possible that they might not have told the truth, especially if they felt comfortable. Furthermore, due to different approaches and scores used may make bit difficult comparison. However, we believe that the approach to testing (groups, anonymity, etc). Also, the sample size of the study was small, and the response rate was low, which can create bias. It is highly recommended that, adequate athletes' trainers nutrition knowledge can improve the standard of care (e.g. injury prevention, rehabilitation) and dietary education is useful in improving dietary intake and nutrition knowledge among athletes.

\section{Conclusions}

The present study demonstrated that athletes' trainers have regular nutrition knowledge and poor health related nutrients disorders knowledge. In addition, gender differences did not influence neither nutrition knowledge nor health related nutrients deficient questions. However, the education levels found to have significant impact on both nutrition knowledge and health related nutrients deficient. Furthermore, dietitians with an expertise in athletes' nutrition are qualified professionals who should be the primary source for obtaining diet information. Dietitians within a sport setting may not be available to the players and thus have limited time to provide nutrition education to the trainers. Validated score for nutrition knowledge needs to be undertaken. Its highly recommended that, adequate athletes' trainers nutrition knowledge can improve the standard of care (e.g. injury prevention, rehabilitation) and dietary education is useful in improving dietary intake and nutrition knowledge among athletes.

\section{Acknowledgment}

We are grateful to all subjects who participated in the study.

\section{Conflict of Interest}

The authors declare no conflicts of interests. 


\begin{abstract}
About the Author(s)
Ali Ateia Elmabsout is Head Department of Nutrition, Faculty of Public Health, University of Benghazi, PhD in Biomedicine, Associated Professor in Nutrition and Biochemistry. Interest area of research are in biomedicine, clinical nutrition, dietetics and biochemistry related fields.
\end{abstract}

\title{
References
}

1. Cotugna N., Vickery C.E., McBee S. 2005. Sports Nutrition for Young Athletes. The Journal of School Nursing 21(6):323-328.

2. Rastmanesh R., Taleban F.A., Kimiagar M., Mehrabi Y., Salehi M. 2007. Nutritional knowledge and attitudes in athletes with physical disabilities. Journal of Athletic Training 42(1):99-105.

3. Torres-McGehee, T.M.; Pritchett, K.L.; Zippel, D.; Minton, D.M.; Cellamare, A.; Sibilia, M. 2012. Sports nutrition knowledge among collegiate athletes, coaches, athletic trainers, and strength and conditioning specialists. J. Athl. Train 47, 205-211.

4. Condon, E.M., Dube, K.A., \& Herbold, N.H. 2007. The influence of the lowcarbohydrate trend on collegiate athletes' knowledge, attitudes, and dietary intake of carbohydrates. Topics in Clinical Nutrition 22(2), 175-184.

5. Dunn, D., Turner, L. W., \& Denny, G. 2007. Nutrition knowledge and attitudes of college athletes. The Sport Journal 10(4), 45.

6. Heaney, S., O'Connor, H., Naughton, G., \& Gifford, J. 2008. Towards an understanding of the barriers to good nutrition for elite athletes. International Journal of Sports Science \& Coaching 3(3), 391-401.

7. Rash, C.L., Malinauskas, B.M., Duffrin, M.W., Barber-Heidal, K., \& Overton, R.F. 2008. Nutrition-related knowledge, attitude, and dietary intake of college track athletes. The Sport Journa 11(1), 48-54.

8. Spendlove, R., Taleban, F.A., Kimiagar, M., Mehrabi, Y., \& Salehi, M. 2015. Nutritional knowledge and attitudes in athletes with physical disabilities. Journal of Athletic Training 42(1), 99-105.

9. Parmenter K., and J. Wardle. 2009. Development of a general nutrition knowledge questionnaire for adults. European Journal of Clinical Nutrition 53, 298-308.

10. Christine A. Karpinski, et al. 2019. Development and Validation of a 49-Item Sports Nutrition Knowledge Instrument (49-SNKI) for Adult Athletes. Top Clin Nutr 34, 3, pp. 174-185

11. Danaher, K.; Curley, T. 2014. Nutrition knowledge and practices of varsity coaches at a Canadian university. Can. J. Diet. Pract. Res 75, 210-213.

12. Spendlove, J.K., Heaney, S.E., Gifford, J.A., Prvan, T., Denyer, G.S., \& O'Connor, H.T. 2012. Evaluation of general nutrition knowledge in elite Australian athletes. The British Journal of Nutrition 107(12), 1871-1880. 
13. Raymond-Barker, P., Petroczi, A., \& Quested, E. 2014. Assessment of nutritional knowledge in female athletes susceptible to the Female Athlete Triad syndrome. Journal of Occupational Medicine and Toxicology (London, England) 2(10).

14. Dunn, D., Turner, L.W. \& Denny, G. 2007. Nutrition knowledge and attitudes of college athletes. The Sport Journal. 10(4).23-30

15. Alaunyte, I.; Perry, J.L.; Aubrey, T. 2015. Nutritional knowledge and eating habits of professional rugby league players: Does knowledge translate into practice? J. Int. Soc. Sports Nutr 12, 18-27

16. Shifflett B., Timm C., Kahanov L. 2002. Understanding of athletes' nutritional needs among athletes, coaches, and athletic trainers. Res Q Exerc Sport 73(3):357- 362.

17. Hamilton, G.J., Thomson, C.D., \& Hopkins, W.G. 2009. Nutrition knowledge of elite distance runners. New Zealand Journal of Sports Medicine 22(2), 26-29.

18. Harrison, J., Hopkins, W.G., MacFarlane, D.J., \& Worsley, A. 2009. Nutrition knowledge and dietary habits of elite and non-elite athletes. Australian Journal of Nutrition and Dietetics 48, 124-127.

19. Zinn, C., Schofield, G., \& Wall, C. 2016. Evaluation of sports nutrition knowledge of New Zealand premier club rugby coaches. International Journal of Sport Nutrition and Exercise Metabolism 16(2), 214-225.

20. Dunn, D., Turner, L.W. \& Denny, G.2010. 2010. Nutrition knowledge and attitudes of college athletes. The Sport Journal.10(4).123-134.

21. Folasire, O.F.; Akomolafe, A.A.; Sanusi, R.A. 2015. Does nutrition knowledge and practice of athletes translate to enhanced athletic performance? Cross-sectional study amongst Nigerian undergraduate athletes. Glob. J. Health Sci 7, 215-225.

22. Heaney, S., O'Connor, H., Gifford, J., \& Naughton, G. 2010. Comparison of strategies for assessing nutritional adequacy in elite female athletes' dietary intake. International Journal of Sport Nutrition and Exercise Metabolism 20(3), 245-256.

23. Heaney, S., O'Connor, H., Michael, S., Gifford, J., \& Naughton, G. 2011. Nutrition knowledge in athletes: A systematic review. International Journal of Sport Nutrition and Exercise Metabolism 21(3), 248-261.

24. Shoaf, L.R.; McClellan, P.D.; Birskovich, K.A. 2016. Nutrition knowledge, interests, and information sources of male athletes. J. Nutr. Educ 18, 243-245.

25. Weeden, A.; Olsen, J.; Batacan, J.; Peterson, T. 2014. Differences in collegiate athlete nutrition knowledge as determined by athlete characteristics. Sport J 17, 1-13.

26. Birkenhead, K.L.; Slater, G. 2015. A review of factors influencing athletes' food choices. Sports Med 45, 1511-1522.

27. Devlin, B.L.; Belski, R. 2015. Exploring general and sports nutrition and food knowledge in elite male Australian athletes. Int. J. Sport Nutr. Exerc. Metab 25, 225-232. 
Ahmed Boumaeza, Ali Ruhaet, Hassan Abdulqader,

Abdelmetalab F. Tarhuni, Isam Danna, Abdulla Sheikhi, Ali Ateia Elmabsout

EVALUATION OF NUTRITION AND HEALTH RELATED NUTRITIOUS

INTAKE KNOWLEDGE AMONG ATHLETES' TRAINERS

Creative Commons licensing terms

Authors will retain the copyright of their published articles agreeing that a Creative Commons Attribution 4.0 International License (CC BY 4.0) terms wil be applied to their work. Under the terms of this license, no permission is required from the author(s) or publisher for members of the community to copy, distribute, transmit or adapt the article content, providing a proper, prominent and unambiguous attribution to the authors in a manner that makes clear that the materials are being reused under permission of a Creative Commons License. Views, opinions and conclusions expressed in this research article are views, opinions and conclusions of the author(s). Open Access Publishing Group and European Journal of Physical Education and Sport Science shall not be responsible or answerable for any loss, damage or liability caused in relation to/arising out of conflict of interests, copyright violations and inappropriate or inaccurate use of any kind content related or integrated on the research work. All the published works are meeting the Open Access Publishing requirements and can be freely accessed, shared, modified, distributed and used in educational, commercial and non-commercial purposes under a Creative Commons attribution 4.0 International License (CC BY 4.0). 